\title{
Humic Acids of Leached Chernozems of Western Siberia as Influenced by Human Impact
}

\author{
Klenov B. M. ${ }^{1}$ \\ ${ }^{1}$ Institute of Soil Science and Agrochemistry of Siberian Branch of Russian Academy of Sciences, Novosibirsk, \\ Russia \\ Correspondence: Klenov B. M., Institute of Soil Science and Agrochemistry of Siberian Branch of Russian \\ Academy of Sciences (ISSA SB RAS), Novosibirsk, Russia. E-mail: kbm1825@ngs.ru; klenov@issa.nsc.ru
}

\author{
Received: March 4, 2014 Accepted: May 5, 2014 Online Published: May 27, 2014 \\ doi:10.5539/enrr.v4n3p51 URL: http://dx.doi.org/10.5539/enrr.v4n3p51
}

\begin{abstract}
As it is known, the formation of soil humus as well as soil formation is controlled by Dokuchaev's five soil-forming factors, i.e by climate, vegetation, relief, soil-forming rock and age of the landscape. In connection with fact that the soil has been subjected by heavy human impact during latest one and a half century, it became necessary to take into account the sixth factor, i.e. the anthropogenic one. As for Western Siberia, despite the relatively young farming (mean age of ploughland is about $80-90$ years) as compared to other parts of the planet, appreciable humus losses have been progressed from the soils. It is especially observed in the soils of chernozem type widely spread in the forest steppe belt. Along with humus losses, the changes of quality of soil organic matter and structure of its principal constituents are in progress. The paper in question deals with the change of the nature of the most sustainable constituent of soil humus such as humic acids (HA). The study has been performed by the example of leached chernozems (Luvic Chernozem) which are widely spread in Western Siberia and used in long-term dry farming as well as under influence of irrigation.
\end{abstract}

Keywords: humic acids (HA), elemental composition, degree of aromaticity (DA), farming, irrigation

\section{Introduction}

It is known that any human impact changes the soil as a physical habitat of organic triad such as plants, soil animals and microorganisms. After dying out all the specimens of the triad serve as a source of soil organic matter, the most part of which is presented by humus. Humus is mainly a system of macromolecular polydisperse heterogeneous and heterochronous (uneven-aged) compounds of acid nature. In general terms, this system was formed during the complicated process of decomposition which is in its turn as a peculiar natural selection of the substances differed by chemical and, consequently, ecological sustainability. Nevertheless, humus is the most vulnerable soil constituent with respect to all the kinds of anthropogenic impact as a whole. It is especially affected by ploughing up. By the example of the most important soil types of Western Siberia it was shown that humus losses amounted to $1 / 3$ of its total reserve in the course of about 100 years of farming (Titlyanova \& Naumov, 1995; Titlyanova \& Kosykh, 1997). Additional evidence was obtained later on even for soils not subjected to erosion; moreover, a review of world literature data permitted to conclude about essential reduction of humus content as well as about the changes of humus quality and the nature of all humus constituents as a result of long-term tillage (Klenov, 2000). Furthermore, it was also reviewed that at present time anthropogenic influence on soil was multiform. By virtue of high chemical activity humic acids (HA) and fulvic acids (FA) interact with pollutants (products of acid rains, heavy metals, and radioactive nuclides a.o.) and neutralize their injurious influence on the soil, but at the same time the soil becomes degraded inevitably.

The study of mechanisms of such interactions is one of topical questions of contemporary soil science. At the same time, the ploughing up of the soil and its long-term use in farming are known to be the most ancient and more closely investigated human impact on the soil. It is also known to a greater or lesser extent about the influence of irrigation on soil physical and chemical properties and organic matter. Based on above-mentioned facts, it should be noted that, on the one hand, the mechanism of losses of soil humus because of its oxidation and erosion has long been known. On the other hand, the mechanisms of structural changes of humus constituents have not yet been clarified properly. In this work an attempt was made to obtain additional evidence on structural changes of HA as influenced by long-term tillage and irrigation. 


\section{Materials and Methods}

Leached chernozem was chosen as an object of the study (Novosibirsk Region), this soil subtype is the main one in the forest steppe of Western Siberia. Furthermore, this soil subtype makes up a considerable part of available arable lands of the given region of Russia.

The soils under study are formed within the limits of the watersheds of Near-Ob-River Plateau. The soils of the total territory under consideration are characterized by satisfactory natural drainage and relative uniformity of soil cover, which is composed by chernozems of different subtypes. Soil-forming rocks are loess-like loams. Primary salinization is lacking. From this it follows that the hazard to display of secondary salinization, over moistening and bogging at strictly normalized irrigation is the least probable here.

Before choosing the plots for studies the total territory of the field of the state farm was examined by using available large-scale soil map 1:25,000. Minimum area of the plot, on which it was possible to note all soil subtypes of Plateau in question, comprises 0.3 ha. It is precisely the plots of such size that were used for additional soil sampling. These plots were previously mapped in detail $(1: 5,000)$. It turned out that microcatenas on such plot consisted of three soil subtypes. Microelevations are occupied by typical chernozem, micro-depressions by podzolized chernozem and intermediate positions fall on leached chernozem. This soil subtype constitutes the main soil background, i.e. $70 \%$ of total area of the plot that is equivalent to 0.2 ha. Three such plots were chosen for soil sampling on non-irrigated and irrigated fields respectively (three variants). 10 samples were taken in the uppermost $20 \mathrm{~cm}$ soil layer more or less evenly from each of these plots and then one composite sample was taken for extraction of HA and FA. As for the virgin variant, the possibilities of sampling were more modest to some degree because of the deficiency of undisturbed areas. Nonetheless, it was possible to select three composite samples from the plot of 0.05 ha. The virgin analogue of virgin soil was used as a pattern. It should be noted that by the moment of sampling (the year 1986) the soils were being used in agriculture for about 100 years. The same total period of practical use was in case of irrigated variant, including 12 years under irrigation. Thus, the irrigation was superimposed on rather old-arable soil. The first data were published earlier (Klenov, 2000) and will be cited here as required. The sampling was repeated in 20 years (in 2005). The data on HA nature are being considered in this paper. The subsequent sampling will be performed in 2015.

It should be pointed out that irrigation system of the state farm is fed by river water. Its total mineralization amounts to 0.4-0.7 $\mathrm{g} \mathrm{L}^{-1}$. Anionic composition is presented by $\mathrm{SO}_{4}{ }^{2-}$ and $\mathrm{HCO}_{3}{ }^{-}$, and cationic by variable combinations of $\mathrm{Na}^{+}, \mathrm{Mg}^{2+}, \mathrm{Ca}^{2+}$ or $\mathrm{Mg}^{2+}, \mathrm{Ca}^{2+}, \mathrm{Na}^{+}$or $\mathrm{Na}^{+}, \mathrm{Ca}^{2+}, \mathrm{Mg}^{2+}$. SAR is 1.5-2.0, hand in hand with mineralization this value bears witness to absence of potential hazard to chernozem alkalinization on irrigation.

The preparations of HA and FA were isolated from all soil samples with the purpose of study on the changes of their structural characteristics influenced by agricultural practice; only HA were considered in this paper because they are as a peculiar marker of ecological sustainability of soil system on the whole. An increased sustainability of HA against a background of all other humus compounds was ascertained earlier by method of radiocarbon dating (Chichagova, 1985). The isolation of the preparations and determination of their cation exchange capacity (CEC) was carried out by generally accepted standard methods (Orlov \& Grishina, 1981). Elemental composition of the preparations, described in this paper, was accomplished by means of analyzer PerkinElmer 2400 Series II CHNS/O Elemental Analyzer.The similar data, published in 2000, were performed by analyzer CHN-1 (Czechoslovakia) which is unsuitable for use because of wear. Therefore, the data of this publication and that of 2000 can be compared but to some extent arbitrarily. The values of atomic ratios of the elements such as $\mathrm{H}: \mathrm{C}$ and $\mathrm{C}: \mathrm{N}$, as well as the degree of aromaticity (DA) were obtained by calculation on a basis of data of elemental analysis as proposed earlier (Orlov \& Grishina, 1981; Orlov, 1990). Statistical data processing was performed by generally accepted procedure. Classical dispersing analysis was conducted by Fischer. The differences of mean data were analyzed by Student. The level of significance was standard (5\%).

\section{Results and Discussion}

The nature of HA is a very broad conception. When studying it, first of all it should be obligatorily foreseen the determination of their elemental composition as well as CEC. Elemental composition and CEC are the most important descriptions of HA. They are used not only to get an idea of HA as a special class of organic substances but also in connection with the study of soil genesis; and lately these descriptions are also used in the study of soils disturbed by human activities.

The data (Table) indicate that HA of all the soils under study are little distinguished from one another by elemental composition. On the whole, basic structural elements are typical for this group of soil humus compounds. Against a background of virgin variant the changes of elemental composition of HA as a result of long-tern practical activity proved to be statistically insignificant. However, the changes of atomic ratios of 
structural elements such as $\mathrm{H}: \mathrm{C}$, especially degree of aromaticity (DA) after prolong irrigation are statistically significant. As for $\mathrm{C}: \mathrm{N}$ ratios, they only indicate to a slight tendency of removal of nitrogen from molecules of $\mathrm{HA}$ as result of ploughing and irrigation. Thus, only DA and to some extent $\mathrm{H}: \mathrm{C}$ ratios can be considered as being the most sensitive and informative index of human impact.It is known besides that the decrease in $\mathrm{C}: \mathrm{H}$ ratio can point to the fact that soil organic acids gain the higher degree of condensation (polymerization) of their molecules (Varadachari \& Ghosh, 1981). As a rule decrease in H:C is accompanied by increase in DA; this fact in its turn is confirmed by data given in the Table 1 . In this case the change of these values is more heavily revealed when the soil is used under irrigation. The irrigation is more destructive impact than long-term ploughing up that was noted by the example of West-Siberian leached chernozem irrigated in the course of 12 years (Klenov, 2000) when the values of H:C and DA proved to be as high as 0.84 and 34 respectively. In general terms, more prolonged irrigation did not favor to further change of molecular structure of HA. More or less similar picture was observed on irrigated soils of European part of Russia (Orlov, 1990). One can assume that all basic structural complete changes at HA occurred most likely in the course of the first 20 years of irrigation. At the same time it should be noted that the most striking changes are revealed within the limits of the ten-year period of irrigation, because $\mathrm{H}: \mathrm{C}$ remain practically unaltered and the changes in elemental composition are negligible. As for structural changes, it would more worthwhile to judge them just from the value of $\mathrm{H}: \mathrm{C}$ as it is as an index of the state of carbonic-hydrogenous "framework". The same 20-year period of stabilization of new level of humus sustainability was revealed in chestnut soils of West-Siberian dry steppe which were also irrigated by weakly mineralized waters (Kovaleva, 1997). At the same time, as it is evidenced in the review of many literature data (Klenov, 2000), the period of time during which arable soils enter into new permanent development stage amounts most often to 30 years. It was rather clearly shown by the example of increase in humus content and deterioration of humus quality. Long-term tillage resulted in decreasing humus content by $1 / 3$ of total content in 30 years. As it is known, humus quality is usually estimated by the change of carbon content ratio $\mathrm{C}_{\mathrm{HA}}: \mathrm{C}_{\mathrm{FA}}$. In 100 years this index declined from 2.3 (virgin soil) to 1.6 (old-arable soil). Moreover, 12-year irrigation led to the further decrease up to 1.4 in $\mathrm{C}_{\mathrm{HA}}: \mathrm{C}_{\mathrm{FA}}$ ratios. Thus, the degradation of humus and entry of soil into new permanent development stage occurs more rapidly under irrigation than under dry-land farming. $\mathrm{N}$ essential change was observed in humus content and in value of $\mathrm{C}_{\mathrm{HA}}: \mathrm{C}_{\mathrm{FA}}$ in following 20 years.

Table 1. Elemental composition of humic acids

\begin{tabular}{|c|c|c|c|c|c|c|c|c|}
\hline \multirow{2}{*}{ Variant } & $\mathrm{C}$ & $\mathrm{H}$ & $\mathrm{N}$ & $\mathrm{O}$ & $\mathrm{H}: \mathrm{C}$ & $\mathrm{O}: \mathrm{C}$ & C:N & D:A \\
\hline & \multicolumn{5}{|c|}{$\%$ of weight of dry ash-free matter } & \multicolumn{3}{|c|}{ Atomic ratios } \\
\hline & \multicolumn{8}{|c|}{ Virgin plot } \\
\hline 1 & 51.8 & 4.4 & 4.0 & 39.8 & 1.01 & 0.57 & 15.1 & 20 \\
\hline 2 & 55.7 & 4.9 & 3.7 & 35.7 & 1.04 & 0.48 & 17.5 & 20 \\
\hline 3 & 54.0 & 4.6 & 3.6 & 37.8 & 1.01 & 0.52 & 17.5 & 19 \\
\hline \multirow[t]{2}{*}{ Mean value } & 53.8 & 4.6 & 3.7 & 37.7 & 1.02 & 0.52 & 16.7 & 19.6 \\
\hline & \multicolumn{8}{|c|}{ Old arable plot (120 years of use) } \\
\hline 1 & 55.8 & 4.4 & 3.4 & 36.4 & 0.93 & 0.49 & 19.1 & 25 \\
\hline 2 & 56.1 & 4.5 & 3.3 & 36.6 & 0.96 & 0.48 & 19.8 & 25 \\
\hline 3 & 54.9 & 4.3 & 3.1 & 37.7 & 0.93 & 0.51 & 20.6 & 24 \\
\hline \multirow[t]{2}{*}{ Mean value } & 55.6 & 4.4 & 3.3 & 36.9 & 0.94 & 0.49 & 19.8 & 24.6 \\
\hline & \multicolumn{8}{|c|}{ Old arable plot (120 years of use, including 30 late years under irrigation) } \\
\hline 1 & 54.1 & 3.8 & 3.9 & 38.3 & 0.84 & 0.53 & 16.2 & 28 \\
\hline 2 & 54.8 & 3.3 & 3.1 & 38.8 & 0.72 & 0.53 & 20.6 & 35 \\
\hline 3 & 55.1 & 3.7 & 3.2 & 38.0 & 0.80 & 0.51 & 20.0 & 32 \\
\hline Mean value & 54.7 & 3.6 & 3.4 & 38.4 & 0.78 & 0.52 & 18.9 & 31.7 \\
\hline $\mathrm{LSD}^{*}{ }_{05}$ & 2.44 & 0.44 & 0.58 & 2.54 & 0.076 & 0.05 & 3.30 & 4.16 \\
\hline
\end{tabular}

The least significant difference. 
It should be noted that on description of elemental analysis of HA the interest is generated to know the behavior of other important structural element such as nitrogen and the value of C:N in particular. Inconsiderable increase in $\mathrm{C}: \mathrm{N}$ in old arable soil as compared to virgin analogue indicates to the tendency of removal on nitrogen from HA molecules. The behavior of this element is complicated in the course of organic matter decomposition. The problem of inclusion of nitrogen into composition of humus acids is one of the most complicated. Until the present time it has not been elucidated a question in what stage of humification and to what degrees enters nitrogen into the structure of humus acids.

Turning the attention to CEC description of HA one should note generally known fact that humus acids define $2 / 3$ of absorbing capacity of soil colloids. Absorbing capacity of humus acids is caused by availability of functional groups in their molecules among of which the carboxyl groups - $\mathrm{COOH}$ play a dominant role. These groups are rather easily renewed, especially in early stages of humus formation (Alexandrova, 1982). These facts indicate that humus acids can comparatively rapidly response to one or another human impact. Inasmuch as HA are predominant among humus acids it seems that these substances can be used as a marker of the change of absorbing capacity of soil influenced by tillage and irrigation. Cation exchange properties of soils of Western Siberia including chernozems were earlier considered rather in detail (Klenov, 2000). This paper adduces only preliminary additional determinations of the change of CEC depending on increase in period of irrigation up to 30 years. In chernozem under consideration CEC of HA changed insignificantly in the course of the whole of history of farming (120 years): its values amounted to 5.0 and $4.5 \mathrm{meq} \mathrm{g}^{-1}$ in virgin and old arable samples respectively. At the same time, subsequent decrease in this value up to 3.5-4.0 meq g-1 occurred in response to 12 -year irrigation. And yet the increase in period of irrigation up to 30 years did not lead to further decrease in CEC. Thus, according to values of CEC, as well as H:C and DA humic acids of chernozem enter into new development stage after first decade after application of irrigation. Decrease in CEC just as increase in DA is unfavorable phenomena in environmental respect. Such changes in structure of HA are as an indicator of weakening of their basic environmental functions to maintain soil fertility. The loss of carboxyl groups leads to gradual conversion of HA into inert material.

All above-mentioned changes in HA-structure take place at the expense of loss of humus when developing soils. In essence, the loss of humus can be defined as a slow proceeding "burning" of organic material. Other distinctions will depend on combination of aerobic and anaerobic conditions; as it is known, the products of oxidation in each of these processes are different. But in any case final products seem to be the same. These are humus acids with high DA. The assumed analogy of burnings is fairly conventional and implies the prevalence of aerobic processes in both cases. Considerable increase in DA at oxidative destruction of organic matter is confirmed by studies on natural and artificial ignition of soil organic matter (Almendros et al., 1988, 1990; Gonzales-Perez et al., 2004; Almendros \& Gonzalez-Vila, 2012). In the newly formed (neogenic) "pyromorphous" humus the noticeable changes were observed in elemental composition of HA in which carbon content ranged, for example, to $70 \%$, hydrogen content was reduced up to $1 \%$ and nitrogen practically up to minute amounts; therefore, C:N ratios grew from 50 up to 140. This is the extreme case of transformation of humus acids. Such "burning" cannot proceed in soils, and yet the trend of the process is practically the same in case of biological losses (at the expense of mineralization). Final products are inert humus acids which lost functional groups completely, whereas a partial loss of functional groups results in changing colloidal and chemical properties of humus acids and finally leads to lowering of CEC and physiological activity of HA (Chukov, 1996, 1997). Their recovery and maintenance at more or less permanent level is provided in event of continual application of organic fertilizers (Reuter, 1981; Wander et al., 1995). Of course, biological loss of humus is a negative process but it is less serious environmental disaster than the loss at the expense of erosion. Soil fertility is determined not only by amount of humus but also by its quality and nature as a whole.

\section{Conclusion}

One should note that the significant and, therefore, most informative indices of elemental composition of humic acids are the values such as $\mathrm{H}: \mathrm{C}$, degree of aromaticity and to a lesser extent $\mathrm{C}: \mathrm{N}$. The change of these indices under human impact on soil cover testifies to the changes of environmental functions of soil organic matter. Specifically, increase in degree of aromaticity of humic acids in arable soils, decrease in $\mathrm{H}: \mathrm{C}$, increase in C:N and decrease in CEC are persuasive indices of degradation of humic acids. Permanent losses of humus along with degradation of its basic components predetermine the barest necessity to perform measures on possible recovery of humus level and prevention of its further losses and degradation. 


\section{References}

Aleksandrova, L. N. (1980). Soil organic matter and the ways of its transformation (p. 288). Leningrad Publisher.

Almendros, G., \& Gonzalez-Vila, F. J. (2012). Wildfires, soil carbon balance and resilient organic matter in Mediterranean ecosystems: A review. Spanish J. Soil Sci., 2(2), 8-198.

Almendros, G., González-Vila, F. J., \& Martin, F. (1990). Fire-induced transformation of soil organic matter from an oak forest.An experimental approach to the effect of fire on humic substances. Soil Sci., 149(3), 158-168. http://dx.doi.org/10.1097/00010694-199003000-00005

Almendros, G., Martin, F., \& Gonzalez-Vila, F. J. (1988). Effect of fire on humus and on humic and lipid fraction in a Distric xerocrept in Spain. Geoderma, 42(2), 115-127. http://dx.doi.org/10.1016/0016-7061(88)90028-6

Chichagova, O. A. (1985). Radiocarbon dating of soil humus (p. 158). Moscow Publisher "Nauka".

Chukov, S. N. (1996). Structural and functional parameters and ecological potential of soil organic matter in contemporary above-ground systems. Proceedings of S.-Pb. University, Series 3 (Biology), 1(3), 48-50.

Chukov, S. N. (1997). Features of contemporary processes of transformation of organic matter and its ecological potential in man-transformed soils. Problems of anthropogenous soil formation. Moscow, 3, 119-123.

Gonzalez-Perez, J. A., Gonzalez-Vila, F. J., Almendros, G., \& Knicker, H. (2004). The effect of fire on soil organic matter - a review. Environment International, 30, 855-870. http://dx.doi.org/10.1016/j.envint.2004.02.003

Klenov, B. M. (2000). Humus sustainability of automorphic soils of Western Siberia (p. 176). Novosibirsk: Novosibirsk, SB RAS Publisher.

Kovaleva,Ye. I. (1997). Change of humus of dry steppe soil with time and under irrigation (by the example of Kulunda steppe). Abstract of thesis of Phyl. Dr., Sci. Biol. Novosibirsk.

Orlov, D. S. (1990). Humus acids and general theory of humification (p. 326). Moscow University Publisher.

Orlov, D. S., \& Grishina, L. A. (1985). Humus chemistry practical work (p. 99). Moscow University Publisher.

Reuter, J. H. (1981). Calculation of molecular weight of humus substances from colligative data.Application of aquatic humus and its molecular size fractions. Geochim. Cosmochim. Acta, 45(11), 2017-2022. http://dx.doi.org/10.1016/0016-7037(81)90056-9

Titlyanova, A. A., \& Kosykh, N. P. (1997). Change of productivityWest-Siberian landscapes as related to different land use (by the example of Novosibirsk Region). Siberian Ecological Journal, 4, 347-359.

Titlyanova, A. A., \& Naumov, A. V. (1995). Carbon losses from soils of Western Siberia as influenced by agricultural use. Soil Science (Pochvovedenie), 11, 57-62.

Varadachari, C., \& Ghosh, K. (1984). On humus formation. Plant a. Soil., 77(2-3), 305-315. http://dx.doi.org/10.1007/BF02182933

Wander, M. M., Traima, S. J., Stinner, B. A., \& Peters, S. E. (1995). Organic and conventional management effects on biologically active soil organic matter pools. Soil Sci. Soc. America, 58(4), 1130-1138. http://dx.doi.org/10.2136/sssaj1994.03615995005800040018x

\section{Copyrights}

Copyright for this article is retained by the author(s), with first publication rights granted to the journal.

This is an open-access article distributed under the terms and conditions of the Creative Commons Attribution license (http://creativecommons.org/licenses/by/3.0/). 